\title{
A Study of Starvation Ketosis in the Ruminant
}

\author{
By A. ROBERTSON AND CHRISTIAN THIN \\ Department of Hygiene and Preventive Medicine, Royal (Dick) School \\ of Veterinary Studies, University of Edinburgh
}

(Received 31 Fuly 1952)

There is a theory of long standing that post-parturient dyspepsia of cattle, or bovine ketosis as it is often called, is caused by an inadequate calorie intake; the same has also been suggested of the condition known as pregnancy toxaemia in ewes. It was felt, therefore, that it might be of value to make a detailed study of starvation ketosis in those animals, especially as earlier experiments appear to have yielded rather conflicting results. Thus Sjollema \& Van der Zande (1923), who carried out one of the earliest experiments on starvation ketosis, came to the conclusion that the cow does not readily produce much acetone unless in certain diseased conditions. Similarly Carpenter ( 1927 ) concluded that the ruminant was quite resistant to starvation ketosis. However, Forbes (I943) claimed to find a rise in blood ketone bodies in lactating cows kept on submaintenance diets for considerable periods, and both Carlström (1950) and Holmes (1950) noted a marked urinary excretion of ketone bodies by cows starved post partum. Similarly, Sampson \& Boley (1940) and Clark, Groenewald \& Malan (1943) produced a starvation ketosis in ewes in late pregnancy, and the latter workers succeeded, by prolonged feeding of inadequate rations, in producing it also in non-pregnant sheep. Few workers, however, have made any really detailed biochemical study of the ketosis observed, and we decided, therefore, to apply to this problem the methods for determining ketone bodies already elaborated by us (Thin \& Robertson, 1952).

\section{METHODS}

Cows. Five cows at peak lactation were kept in their ordinary stalls for a period of from 5 to 6 days without access to food or bedding but with an adequate water supply. The diet before and after the starvation period was the normal for the time of year, though in winter, on resumption of feeding, only hay and roots were given for the first few days and concentrates added later. In addition four dry cows, two non-pregnant and two approaching parturition, were similarly treated, together with two cows with subclinical ketosis; one cow in mid-lactation was kept for a week on a maintenance diet only.

Immediately before, during and for a short time after the starvation period, daily samples of blood, rumen contents, milk (where available) and urine were collected, the blood being obtained usually from the mammary vein and the rumen contents by stomach tube. Daily milk yields were noted, and in some instances, $24 \mathrm{~h}$ samples of urine were collected.

Ewes. Two ewes in the last fortnight of pregnancy and one non-pregnant ewe were 
kept in metabolism pens for 4 or 5 days without access to food or bedding but with water $a d$ lib. In these animals, only blood samples were taken daily for analysis.

Estimations. In all samples each of the individual ketone bodies, acetone, acetoacetic acid and $\beta$-hydroxybutyric acid was estimated and in addition isopropanol (Thin \& Robertson, 1952) which had been noticed to occur in post-parturient dyspepsia and in pregnancy toxaemia (Robertson, Thin \& Stirling, 1950). Blood-sugar determinations were made in the cattle experiments by the method of Hagedorn \& Jensen (1923) and volatile fatty-acids in the rumen were estimated by McAnally's (194I) modification of Friedemann's (1938) steam distillation method and Elsden's (1946) chromatographic technique; in some instances the $\mathrm{pH}$ of the rumen liquor was determined electrometrically.

Cows

RESULTS

Volatile acids. The total volatile fatty-acid content of the rumen samples fell sharply on starvation in all cows, the fall being followed by a rise after refeeding (see Fig. $x$, which shows the average figures for the five animals at peak lactation). Each

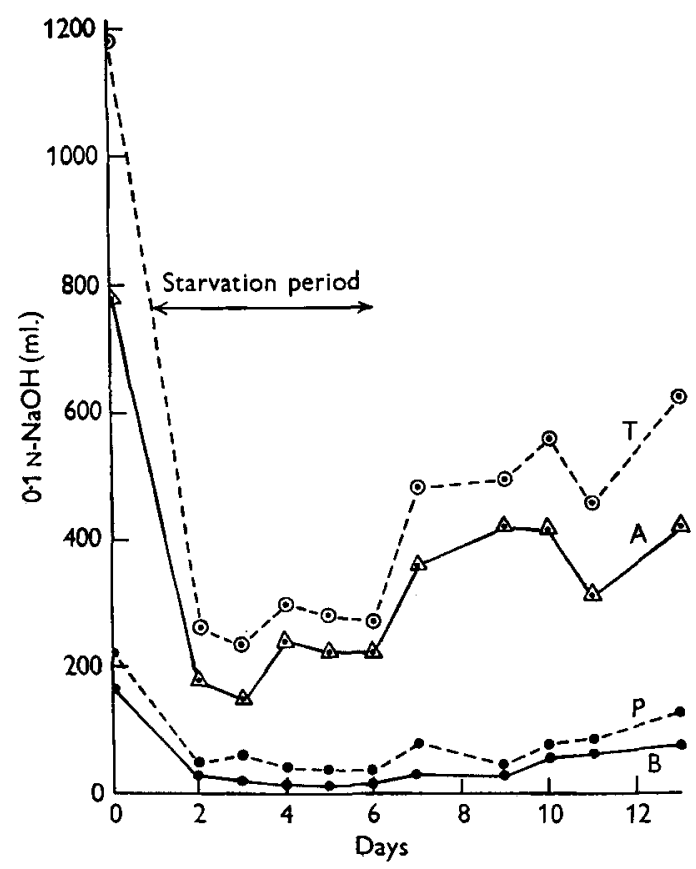

Fig. I. Effect of starvation on the volatile fatty acids in the rumen. $T$, total volatile fatty acids; $A$, acetic acid; $P$, propionic acid; $B$, butyric acid.

of the three individual acids, acetic, propionic and butyric, fell by amounts roughly proportional to their initial concentrations. These changes in concentration with starvation were statistically significant at the $0.1 \%$ level. The unexpected increase in total volatile fatty acids noted on the $3^{\text {rd }}$ day of starvation, after the minimum value reached on the and day, was also statistically significant. The trend in total volatile 
fatty-acid levels after refeeding was also somewhat unexpected, as the initial increase apparently received a setback, the levels on the $5^{\text {th }}$ day of refeeding being slightly lower than those on the $4^{\text {th }}$ and 7 th days.

$p H$ of the rumen contents. Associated with these changes in total volatile fatty acids in the rumen contents, were the changes in $\mathrm{pH}$ shown in three lactating animals for which estimations were made (Table $\mathrm{I}$ ). The $\mathrm{pH}$ of the rumen contents rose on starving from an average value of 6.8 at the outset to a maximum value of 8.4 on the 2nd day of starvation, followed by a fall to 7.4 on the 5 th day. After refeeding commenced, the average $\mathrm{pH}$ value fluctuated appreciably from day to day within the range $6 \cdot 5-7 \cdot 5$.

Table r. $p H$ of rumen contents of the corvs

\begin{tabular}{|c|c|c|c|c|c|c|}
\hline \multirow[b]{2}{*}{ Cow no. } & \multicolumn{6}{|c|}{ Day of starvation } \\
\hline & $\circ$ & I & 2 & 3 & 4 & 5 \\
\hline 3 & 6.4 & $8 \cdot 0$ & $8 \cdot 6$ & $8 \cdot 2$ & $7 \cdot 7$ & $7 \cdot 8$ \\
\hline 37 & $7 \cdot 3$ & 一 & 8.9 & $7 \cdot 6$ & $7 \cdot 2$ & $6 \cdot 7$ \\
\hline 27 & 6.6 & $8 \cdot 5$ & $7 \cdot 7$ & $7 \cdot 8$ & $7 \cdot 7$ & $7 \cdot 7$ \\
\hline Mean & 6.8 & $8 \cdot 3$ & $8 \cdot 4$ & $7 \cdot 9$ & $7 \cdot 5$ & $7 \cdot 4$ \\
\hline
\end{tabular}

Table 2. Daily milk yield of the cows (lb.)

\begin{tabular}{|c|c|c|c|c|c|c|c|c|c|c|c|c|c|}
\hline \multirow[b]{3}{*}{ ow no. } & \multirow{2}{*}{\multicolumn{6}{|c|}{ Day of starvation }} & \multirow{2}{*}{\multicolumn{7}{|c|}{ Day of refeeding }} \\
\hline & & & & & & & & & & & & & \\
\hline & 0 & $I$ & 2 & 3 & 4 & 5 & I & 2 & 3 & 4 & 5 & 6 & 7 \\
\hline 3 & $47 \cdot 5$ & 23 & 17 & I3 & $14^{\circ}$ & II.O & $13 \cdot 0$ & I & 0 & 15.5 & 16.5 & 20.5 & 23 \\
\hline 10 & 33.5 & $22^{\circ}$ & 17. & 12 & $9 \cdot 0$ & I4 & $14^{\circ} \mathrm{C}$ & 12.5 & $16 \cdot 0$ & I8 & $1 \cdot 5$ & 5 & \\
\hline 13 & 60 & 30 & 17 & 16. & $13 \cdot 0$ & & & $\mathrm{II}^{\circ}$ & & $16 \cdot 0$ & 10 & 5 & \\
\hline 20 & $78 \cdot 0$ & $38 \cdot 0$ & $26 \cdot 0$ & 25 & 19.0 & $20 \cdot 0$ & $18 \cdot 0$ & 40.5 & $43 \cdot 5$ & $5^{1 \cdot 0}$ & $5 \cdot 0$ & 54.5 & 55 \\
\hline 37 & $45^{\circ} \circ$ & $33 \cdot 5$ & I 4.0 & $\mathbf{r}_{3} \cdot 0$ & 5 & $7 \cdot 0$ & $5^{\circ} 0$ & $4 \cdot 5$ & $7 \cdot 0$ & 6.0 & $11 \cdot 0$ & $7 \cdot 0$ & \\
\hline Mean & $52 \cdot 9$ & 29.4 & I8:3 & I 5.9 & $12 \cdot 7$ & $13 \cdot 1$ & I I.7 & 16.7 & $18 \cdot 0$ & $21 \cdot 4$ & $24 \cdot 2$ & 25.4 & 20 \\
\hline
\end{tabular}

B. 13 weeks after parturition

Day on maintenance diet

\begin{tabular}{|c|c|c|c|c|c|c|c|c|c|c|c|c|c|}
\hline \multirow{2}{*}{ Cow no. } & \multicolumn{7}{|c|}{ 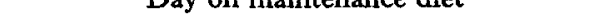 } & \multicolumn{6}{|c|}{ an } \\
\hline & 0 & I & 2 & 3 & 4 & 5 & 6 & I & 2 & 3 & 4 & 5 & 0 \\
\hline & $36 \cdot 5$ & 30.5 & 24.0 & $22 \cdot 5$ & 22.5 & 23.5 & $22 \cdot 0$ & $26 \cdot 5$ & $28 \cdot 0$ & 30.0 & $32 \cdot 5$ & $35^{\circ} \circ$ & 34 \\
\hline
\end{tabular}

C. Cow with subclinical ketosis

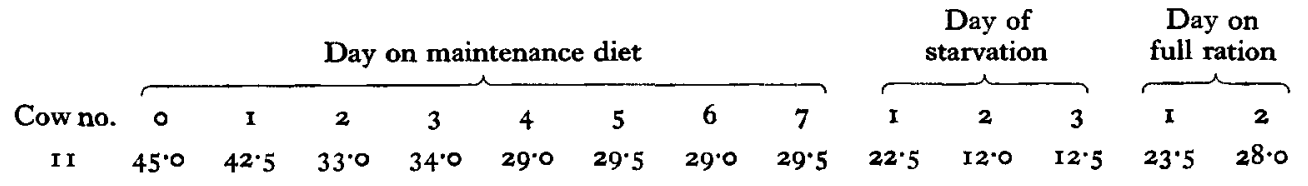

Milk yield. All cows showed a rapid and significant fall in milk yield on starvation (Table 2). The rate of fall of milk yield of the cows at peak lactation was very marked at first but became more gradual towards the $5^{\text {th }}$ day, when the average yield of milk was $\mathrm{I} 3 \mathrm{lb}$. On refeeding, the recovery in milk yield over the period studied was slow, especially with cow no. 37 which showed marked loss of condition during the starvation period. Semi-starvation of a cow I 3 weeks after parturition and of one with subclinical ketosis caused a drop in milk yield, but the rate of fall was much less marked than that 
described above, and the average milk yield reached on the 4 th day of reduced feeding was $25.5 \mathrm{lb}$., compared to $40.5 \mathrm{lb}$. in the pre-fast period. After 7 days on a maintenance diet the cow with subclinical ketosis was starved completely for 3 days, when the milk yield fell still further to $12 \mathrm{lb}$.

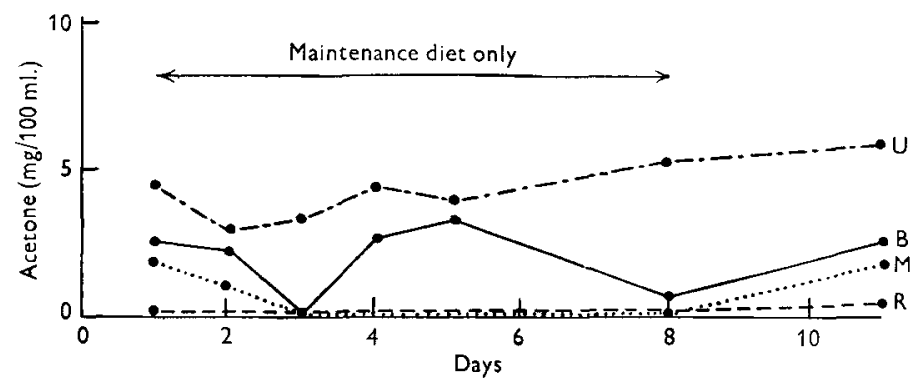

Fig. 2. Effect of a maintenance diet on the ketone bodies, expressed as acetone, of a cow at mid-lactation. ( $\beta$-Hydroxybutyric acid was the only ketone body present.) $B$, blood; $R$, rumen contents; $M$, milk; $\mathrm{U}$, urine.

Ketone bodies. Removal of concentrates from the diet of a cow at mid-lactation caused no rise in blood ketone bodies (Fig. 2). During the whole of the experiment only $\beta$-hydroxybutyric acid was present in the blood, rumen contents, milk and urine, and although the amount present varied from day to day it was well within the normal range, namely below $10 \mathrm{mg} / 100 \mathrm{ml}$, in the blood. Similar results were obtained with the dry non-pregnant cows subjected to complete starvation, the maximum value of total blood ketone bodies reached being $9.6 \mathrm{mg} / \mathrm{roo} \mathrm{ml}$. expressed as acetone; traces of acetone and acetoacetic acid were detected on the $4^{\text {th }}$ and $5^{\text {th }}$ day of starvation, otherwise only $\beta$-hydroxybutyric acid was present.

\section{Table 3. Blood ketones in a dry cow starved during late pregnancy, expressed in $\mathrm{mg}$ acetone/100 $\mathrm{ml}$.}

$\quad$ Blood ketones
Acetone
Acetoacetic acid
$\beta$-Hydroxybutyric acid
Isopropanol
Total ketone bodies

\begin{tabular}{clcccc}
\multicolumn{5}{c}{ Day of starvation } \\
\hline 0 & $I$ & 2 & 3 & 4 & 5 \\
0 & 0 & 0.6 & $1 \cdot 5$ & 4.6 & 12.6 \\
0 & 0 & 0.1 & 0.8 & 3.1 & 1.8 \\
10.7 & 7.4 & 14.8 & $21 \cdot 5$ & 24.9 & 30.4 \\
0 & 0 & 0 & 0.1 & 0.2 & 0.6 \\
10.7 & 7.4 & 15.5 & 23.9 & 32.8 & 45.4
\end{tabular}

Complete starvation of a dry cow about a month before calving caused a marked rise in blood ketone bodies (Table 3). Starvation was commenced in the afternoon, and in the $12 \mathrm{~h}$ between the first two samples no significant change was noted, but subsequent samples showed a progressive increase in all the ketone bodies. The greatest rise was encountered in the $\beta$-hydroxybutyric-acid fraction. Free acetone rose from an almost negligible amount on the 2 nd day to over $27 \%$ of the total on the $5^{\text {th }}$ day of fast, a sharp rise occurring on the $4^{\text {th }}$ and $5^{\text {th }}$ days. Acetoacetic acid 
showed a more gradual rise than acetone, attaining a maximum value of $9 \%$ of the total ketone bodies on the $4^{\text {th }}$ day, with a subsequent fall on the $5^{\text {th. The rise in }}$ isopropanol concentration was very slight, the maximum concentration reached being about $\mathrm{r} \%$ of the total ketone bodies on the $5^{\text {th }}$ day of fast. Similar, though somewhat less well-marked, results were obtained in a pregnant heifer starved during the last 4 days preceding parturition.

Table 4. Mean values for ketone bodies in five starved cows at peak lactation, expressed in $\mathrm{mg}$ acetone $/ 100 \mathrm{ml}$.

\begin{tabular}{|c|c|c|c|c|c|c|c|}
\hline \multirow[b]{2}{*}{ Body fluid } & \multirow[b]{2}{*}{ Ketone bodies } & \multicolumn{6}{|c|}{ Day of starvation } \\
\hline & & o & $\mathbf{I}$ & 2 & 3 & 4 & 5 \\
\hline \multirow[t]{2}{*}{ Blood } & $\begin{array}{l}\text { Acetone } \\
\text { Acetoacetic acid } \\
\beta \text {-Hydroxybutyric acid } \\
\text { Isopropanol }\end{array}$ & $\begin{array}{l}0 \\
0 \cdot 7 \\
6 \cdot 0 \\
0\end{array}$ & $\begin{array}{l}1 \cdot 5 \\
1 \cdot 6 \\
8 \cdot 8 \\
0\end{array}$ & $\begin{array}{r}4 \cdot 5 \\
3 \cdot 0 \\
14 \cdot 5 \\
0.3\end{array}$ & $\begin{array}{r}9 \cdot 0 \\
4 \cdot 6 \\
16 \cdot 7 \\
1 \cdot 6\end{array}$ & $\begin{array}{r}13 \cdot 4 \\
5 \cdot 3 \\
12 \cdot 3 \\
1 \cdot 6\end{array}$ & $\begin{array}{r}15 \cdot 1 \\
4 \cdot 4 \\
23 \cdot 5 \\
1 \cdot 9\end{array}$ \\
\hline & Total ketone bodies & 6.7 & I I 9 & $22 \cdot 3$ & $31 \cdot 9$ & $32 \cdot 6$ & $44 \cdot 9$ \\
\hline \multirow[t]{2}{*}{ Rumen liquor } & $\begin{array}{l}\text { Acetone } \\
\text { Acetoacetic acid } \\
\beta \text {-Hydroxybutyric acid } \\
\text { Isopropanol }\end{array}$ & $\begin{array}{l}0 \\
0.2 \\
3 \cdot 7 \\
0\end{array}$ & $\begin{array}{l}0.9 \\
0.3 \\
5.5 \\
0.5\end{array}$ & $\begin{array}{l}2 \cdot 5 \\
1 \cdot 3 \\
4 \cdot 9 \\
I \cdot 1\end{array}$ & $\begin{array}{l}5 \cdot 5 \\
0 \cdot 8 \\
8 \cdot 5 \\
3 \cdot 3\end{array}$ & $\begin{array}{l}9 \cdot 7 \\
x \cdot 2 \\
6 \cdot 4 \\
5 \cdot 2\end{array}$ & $\begin{array}{r}\text { II.5 } \\
1 \cdot 7 \\
4 \cdot 0 \\
5 \cdot 5\end{array}$ \\
\hline & Total ketone bodies & 3.9 & $7 \cdot 2$ & $9 \cdot 8$ & $I 8 \cdot I$ & $22 \cdot 5$ & $22 \cdot 7$ \\
\hline \multirow[t]{2}{*}{ Milk } & $\begin{array}{l}\text { Acetone } \\
\text { Acetoacetic acid } \\
\beta \text {-Hydroxybutyric acid } \\
\text { Isopropanol }\end{array}$ & $\begin{array}{l}0 \\
0 \\
4 \cdot 9 \\
0\end{array}$ & $\begin{array}{l}I \cdot 4 \\
0 \cdot 3 \\
5 \cdot 4 \\
0 \cdot 1\end{array}$ & $\begin{array}{r}3 \cdot 6 \\
2 \cdot 7 \\
10 \cdot 8 \\
0 \cdot 2\end{array}$ & $\begin{array}{r}8 \cdot 7 \\
0 \cdot 8 \\
16 \cdot 0 \\
1 \cdot 1\end{array}$ & $\begin{array}{r}14 \cdot 5 \\
1 \cdot 8 \\
8 \cdot 5 \\
1 \cdot 4\end{array}$ & $\begin{array}{r}16.2 \\
1.6 \\
7.9 \\
1.8\end{array}$ \\
\hline & Total ketone bodies & 4.9 & $7 \cdot 2$ & $17 \cdot 3$ & $26 \cdot 6$ & $26 \cdot 2$ & 27.5 \\
\hline Urine & $\begin{array}{l}\text { Acetone } \\
\text { Acetoacetic acid } \\
\beta \text {-Hydroxybutyric acid } \\
\text { Isopropanol }\end{array}$ & $\begin{array}{l}1 \cdot 0 \\
3 \cdot 4 \\
11 \cdot 7 \\
0\end{array}$ & $\begin{array}{r}6 \cdot 1 \\
31 \cdot 3 \\
19 \cdot 0 \\
0 \cdot 2\end{array}$ & $\begin{array}{r}8 \cdot 9 \\
3 I \cdot I \\
8 \cdot 6 \\
0 \cdot 5\end{array}$ & $\begin{array}{l}16 \cdot 0 \\
80 \cdot 4 \\
53 \cdot 1 \\
12 \cdot 1\end{array}$ & $\begin{array}{r}25^{\circ} \circ \\
40^{\circ} \cdot \\
35^{\circ} \cdot \\
2 \cdot 9\end{array}$ & $\begin{array}{r}22 \cdot 0 \\
37 \cdot 3 \\
25 \cdot 1 \\
4 \cdot 6\end{array}$ \\
\hline & Total ketone bodies & $I 6 \cdot I$ & $56 \cdot 6$ & $49^{\circ} I$ & $16 r \cdot 6$ & $104 \cdot 2$ & $89 \cdot 0$ \\
\hline
\end{tabular}

The five cows starved at peak lactation all showed a considerable degree of ketonaemia, as shown in Table 4, which gives the average figures for all the animals, and Figs. $3-6$, which show the variations in individual constituents in a representative cow. This ketonaemia was associated with loss of condition and a fall in milk yield without any sign of illness or subsequent loss of appetite.

As will be noted, the rise in total ketone bodies on starvation was progressive and highly significant. A statistical study of the whole series of estimations on the three body fluids, blood, rumen liquor and milk, showed the following equations for the regression of concentration of total ketone bodies on days of starvation:

$\begin{array}{ll}\text { Blood } & y=6 \cdot 3+7 \cdot 5 x, \\ \text { Rumen contents } & y=3 \cdot 5+4 \cdot 2 x, \\ \text { Milk } & y=5 \cdot 4+5 \cdot 1 x,\end{array}$

where $y=$ the concentration of total ketone bodies expressed as $\mathrm{mg}$ acetone/100 $\mathrm{ml}$. and $x=$ the day of starvation. 


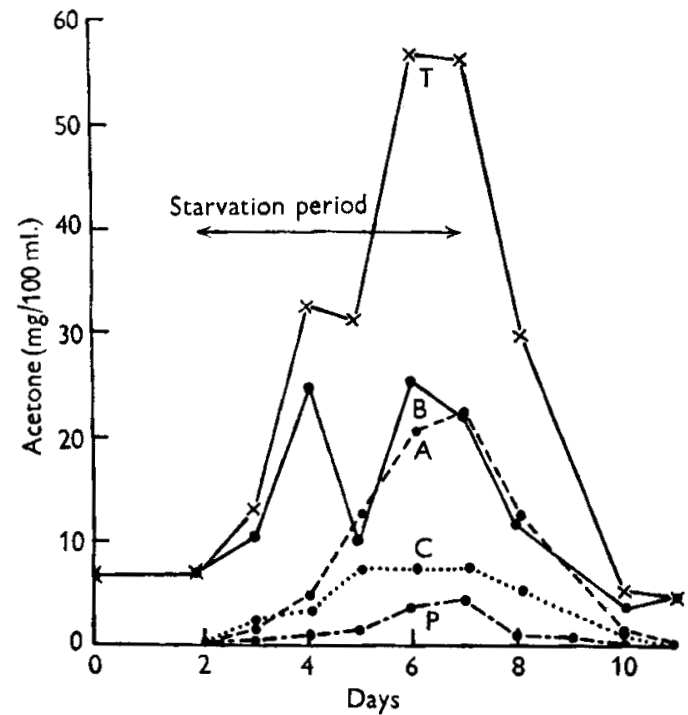

Fig. 3. Effect of starvation on the blood ketone bodies, expressed as acetone, of a cow at peak lactation. $\mathrm{T}$, total ketone bodies; $\mathrm{A}$, acetone; $\mathrm{C}$, acetoacetic acid; $\mathrm{B}, \beta$-hydroxybutyric acid; $\mathrm{P}$, isopropanol.

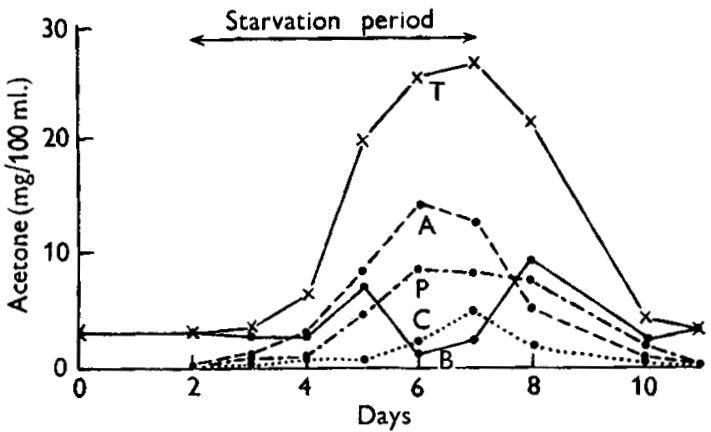

Fig. 4. Effect of starvation on the rumen ketone bodies, expressed as acetone, of a cow at peak lactation. $\mathrm{T}$, total ketone bodies; $\mathrm{A}$, acetone; $\mathrm{C}$, acetoacetic acid; $\mathrm{B}, \boldsymbol{\beta}$-hydroxybutyric acid; $\mathrm{P}$, isopropanol.

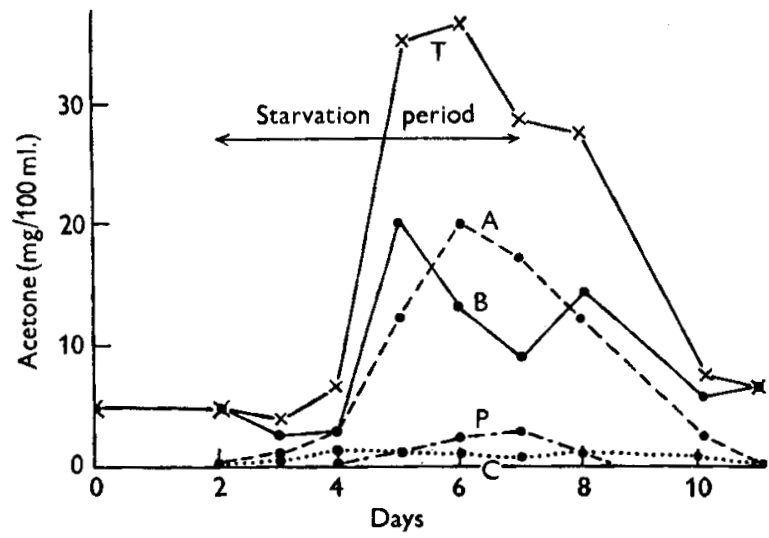

Fig. 5. Effect of starvation on the milk ketone bodies, expressed as acetone, of a cow at peak lactation. $\mathrm{T}$, total ketone bodies; $\mathrm{A}$, acetone; $\mathrm{C}$, acetoacetic acid; $\mathrm{B}, \beta$-hydroxybutyric acid; $\mathrm{P}$, isopropanol. 
The rate of rise of total ketone bodies on starvation in blood and milk was very similar, with the average level in the milk some $5 \mathrm{mg}$ acetone/roo ml. lower than in the blood. Comparison of blood and rumen contents showed that the total ketone bodies on starvation rose less sharply in the rumen fluid than in the blood, and that the average level was some $9 \mathrm{mg}$ acetone/roo $\mathrm{ml}$. lower in the rumen liquor. On refeeding, the decline in total ketone bodies was rapid and by the 4th day had approached the pre-starvation level.

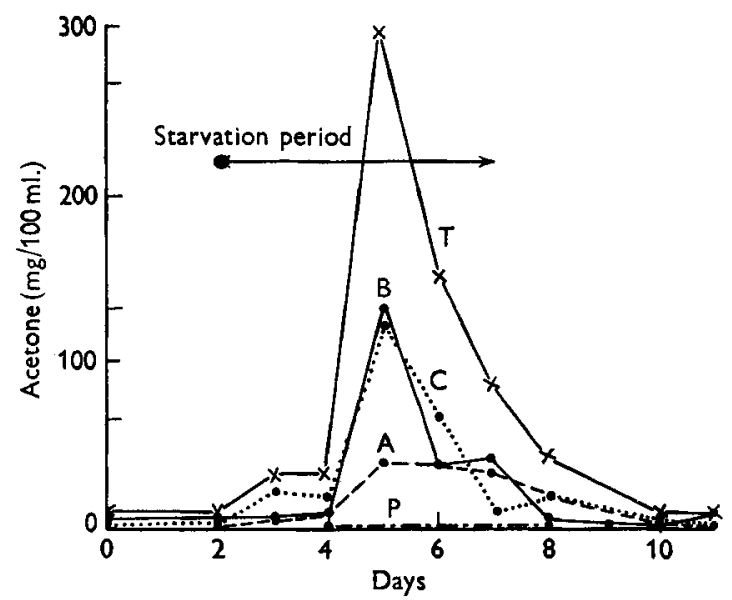

Fig. 6. Effect of starvation on the urine ketone bodies, expressed as acetone, of a cow at peak lactation. $\mathrm{T}$, total ketone bodies; A, acetone; C, acetoacetic acid; B, $\beta$-hydroxybutyric acid; $\mathrm{P}$, isopropanol.

Of the individual ketone bodies, free acetone was one of the most prominent constituents in blood, rumen liquor and milk, rising from negligible amounts at the beginning to some $40-50 \%$ of the total on the 4 th or $5^{\text {th }}$ days of starvation. As with the total ketone bodies, the increase over the starvation range studied was essentially linear, and equal to $3.4,2.8$ and $3.6 \mathrm{mg}$ acetone/ $100 \mathrm{ml}$./day for blood, rumen contents and milk, respectively.

Acetoacetic acid showed a more gradual rise than acetone in the blood, attaining a value of $16 \%$ of the total ketone bodies on the 4 th day, with a subsequent fall to

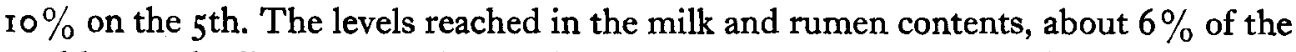
total ketone bodies, were maintained with minor fluctuations throughout the experiment except for a sudden rise to about $14 \%$ of the total ketone bodies on the 2nd day of starvation. As with the total ketone bodies and free acetone, the increase over the starvation range studied was essentially linear, and equal to $0.7,0.5$ and $0.3 \mathrm{mg}$ acetone/roo ml./day for blood, rumen liquor and milk, respectively.

$\beta$-Hydroxybutyric acid showed a rise in the blood over the period of starvation much the same as that of free acetone, though the percentage content fell to $38 \%$ of the total on the $4^{\text {th }}$ day of starvation compared to $90 \%$ of the total ketone bodies in the normal state. The levels in the milk and rumen liquor behaved, with slight variations, very much the same during the starvation period, attaining a point of maximum concentration of 16 and $8 \mathrm{mg}$ acetone/ $100 \mathrm{ml}$., respectively, on the $3^{\text {rd day }}$ 
of starvation. The percentage in the rumen liquor showed a much greater fall than in the blood and milk, dropping to some $17 \%$ of the total ketone bodies on the 5 th day of starvation, compared to $28 \%$ in milk. The increase over the starvation range studied was again essentially linear and equal to $2.9,0.2$ and $0.9 \mathrm{mg}$ acetone $/ 100 \mathrm{ml}$./ day for blood, rumen contents and milk, respectively.

Isopropanol showed a more gradual rise than free acetone in the rumen liquor, attaining the value of $24 \%$ of the total ketone bodies on the 5 th day of starvation. The levels reached in the blood and milk were much lower, $5 \%$ and $6 \%$ of the total ketone bodies, the increase over the range studied being essentially linear and equal to $0.6, \mathrm{I} \cdot \mathrm{I}$ and $0.4 \mathrm{mg}$ acetone $/ \mathrm{ro0} \mathrm{ml} . /$ day for blood, rumen contents and milk, respectively.

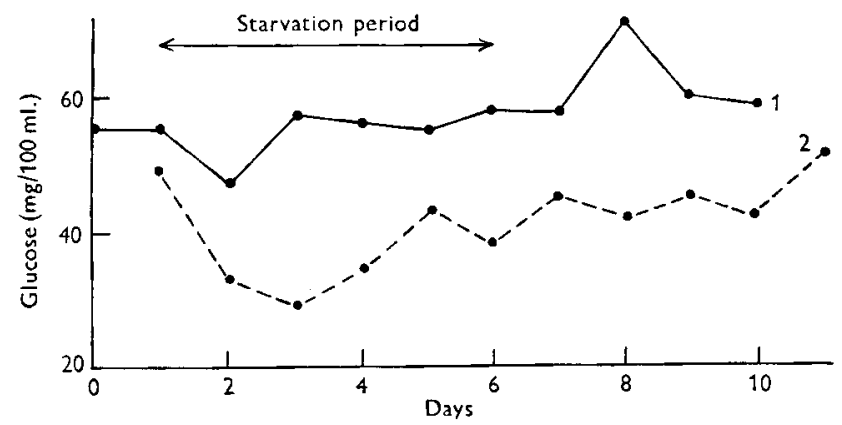

Fig. 7. Effect of starvation on the blood-sugar levels. I, mean for five cows at peak lactation; 2 , cow with subclinical ketosis.

All the cows studied showed in starvation an increase in the total ketone bodies excreted in the urine, the most prominent fraction being usually acetoacetate which, at times, reached concentrations of more than $50 \%$ of the total ketone bodies present; $\beta$-hydroxybutyric acid, acetone and isopropanol were also excreted, but in decreasing proportions in that order. Normally only $\beta$-hydroxybutyric acid is excreted.

Blood sugar. The cows starved at peak lactation all showed a statistically insignificant fall in blood sugar on the Ist day of starvation (Fig. 7) with a subsequent rise to the pre-starvation level on the 2 nd or 3 rd days. There was a slight temporary rise on refeeding. Only two of the cows showed a fall in the blood-sugar value to below the normal range. In cow no. 37 , which lost condition markedly and whose milk yield remained low, the blood-sugar value continued to rise on refeeding, reaching a value above the normal range before returning to the pre-starvation level. One cow gave abnormally high values on the ist day of starvation and on refeeding, probably associated with the fact that she was in a very excited state on these occasions.

Effect of starvation on cows with subclinical ketosis. Starving a cow with subclinical ketosis (Figs. 8 and 9) gave results somewhat similar to those obtained with starving cows at peak lactation. In the pre-experimental period cow no. 27 showed a fair degree of ketosis, though the predominant ketone body present in the blood was $\beta$-hydroxybutyric acid, which fell rapidly on starvation. The response of the total ketone bodies and the constituent fractions, other than $\beta$-hydroxybutyric acid, in both the blood and rumen was much the same as above except for isopropanol in the 
rumen contents. The relative proportions of this fraction fell, as the concentration remained more or less steady. In another cow in which the ketosis in the pre-starvation period was not so severe, all the ketone bodies in the blood, rumen liquor and milk

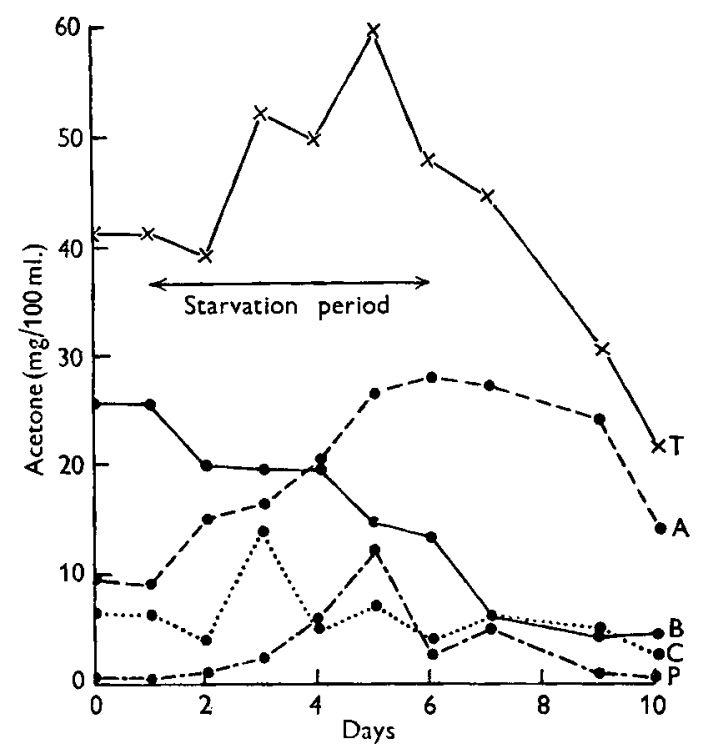

Fig. 8. Effect of starvation on the levels of ketone bodies, expressed as acetone, in the blood of cow no. 27 with subclinical ketosis. $T$, total ketone bodies; $A$, acetone; $C$, acetoacetic acid; $B, \beta$ hydroxybutyric acid; $\mathrm{P}$, isopropanol.

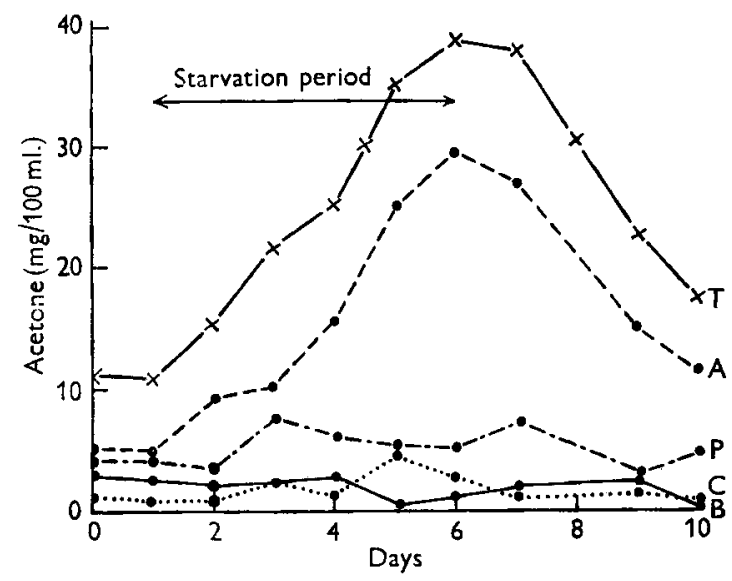

Fig. 9. Effect of starvation on the levels of ketone bodies, expressed as acetone, in the rumen of cow no. 27 with subclinical ketosis. $T$, total ketone bodies; $A$, acetone; $C$, acetoacetic acid; $\mathrm{B}$, $\beta$-hydroxybutyric acid; $\mathrm{P}$, isopropanol.

responded in the same manner to starvation. In these animals, acetoacetate and $\beta$-hydroxybutyric acid were again the main excretory products in the urine. Blood sugar was determined in only one of the cows with subclinical ketosis. The value lay 
just within the normal range in the pre-experimental phase and fell on starving to about $30 \mathrm{mg}$ glucose $/ 100 \mathrm{ml}$. It rose again gradually before refeeding and reached the normal value of about $50 \mathrm{mg}$ glucose/100 ml. a short time later (Fig. 7).

Table 5. Blood ketone bodies in the fasting ewe, expressed in $\mathrm{mg}$ acetone/100 $\mathrm{ml}$.

Blood ketones

\section{Acetone}

Acetoacetic acid

$\beta$-Hydroxybutyric acid

Isopropanol

Total ketone bodies

Acetone
Acetoacetic acid
$\beta$-Hydroxybutyric acid
Isopropanol
Total ketone bodies

\section{Acetone}

Acetoacetic acid

$\beta$-Hydroxybutyric acid Isopropanol

Total ketone bodies

\begin{tabular}{|c|c|c|c|c|}
\hline \multicolumn{5}{|c|}{ Day of starvation } \\
\hline 0 & I & 2 & 3 & 4 \\
\hline \multicolumn{5}{|c|}{ Non-pregnant ewe } \\
\hline 0 & 0 & 0 & 0 & 0.8 \\
\hline 0 & 0 & 0 & $I \cdot 2$ & 0.9 \\
\hline I I 7 & $I O \cdot I$ & I 6.8 & 10.9 & 20.3 \\
\hline 0 & 0 & 0 & 0 & 0.3 \\
\hline $11 \cdot 7$ & IO.I & 16.8 & I 2*I & $22 \cdot 3$ \\
\hline \multicolumn{5}{|c|}{ Pregnant ewe A } \\
\hline $8 \cdot 1$ & $8 \cdot I$ & 10.4 & $1 I^{\circ} 0$ & $12 \cdot 6$ \\
\hline $5 \cdot 4$ & I $8 \cdot 4$ & $9 \cdot 9$ & $6 \cdot 9$ & $9 \cdot 9$ \\
\hline $16 \cdot I$ & $12 \cdot 5$ & $39 \cdot 2$ & $23 \cdot 2$ & $54 \cdot 4$ \\
\hline 0.2 & $\mathbf{I} \cdot \mathbf{I}$ & 0.8 & 0.2 & 0.6 \\
\hline $29 \cdot 8$ & $40 \cdot 1$ & $60 \cdot 3$ & $4 I \cdot 3$ & $76 \cdot 5$ \\
\hline \multicolumn{5}{|c|}{ Pregnant ewe B } \\
\hline 0.6 & 0.8 & 0.5 & - & 一 \\
\hline 0.1 & $I \cdot 5$ & $I \cdot 6$ & - & - \\
\hline $12 \cdot 9$ & $22 \cdot 8$ & $12 \cdot 3$ & - & - \\
\hline 0 & 0 & 0 & - & - \\
\hline $13 \cdot 6$ & $25^{\cdot} I$ & $14 \cdot 4$ & - & - \\
\hline
\end{tabular}

\section{Ewes}

The total ketone bodies rose in the blood of a non-pregnant ewe during starvation,

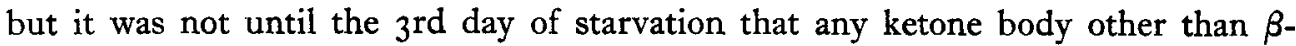
hydroxybutyric acid was found (Table 5). At this time a small percentage of acetoacetic acid was found, and on the $4^{\text {th }}$ day traces of acetone and isopropanol also appeared.

Though the pregnant ewe A appeared normal in all respects, she was found at the commencement of the experiment to have a subclinical ketosis, all four ketone bodies being present in the blood. The rise in total ketone bodies on starvation was progressive and associated with a rise in all the constituent fractions. The greatest rise was encountered in $\beta$-hydroxybutyric acid and the least in the isopropanol fraction. This ewe lambed normally 2 days after refeeding.

Pregnant ewe $\mathrm{B}$ also showed the commencement of ketonaemia in the pre-starvation period, though much less severe than that found in ewe A. Starvation produced an increase in total ketone bodies, as in the previous case, with a rise in acetoacetic acid after the Ist day of starvation. This animal lambed after 2 days of starvation and the blood sample taken immediately afterwards showed a drop in total ketone bodies.

None of the sheep showed signs of illness at any time or any loss of appetite after the starvation period. 


\section{DISCUSSION}

The $\mathrm{pH}$ values estimated for the rumen liquor would be higher than the actual values in the rumen itself owing to the loss of carbon dioxide on removal from the rumen, but it is evident nevertheless that a rise in $\mathrm{pH}$ does occur on starving, coinciding, as would be expected, with the fall in volatile fatty acids. This fall is itself easily understood, as bacterial action in the rumen is bound to decrease owing to lack of substrate. This was confirmed by concurrent bacteriological studies to be reported elsewhere. The fact that all three acids, acetic, butyric and propionic, fall in about the same proportion suggests that the formation of each is equally affected. The slight rise encountered towards the end of the starvation period may be associated with a change in the volume of the rumen contents.

The figures for ketone bodies quoted above corroborate the findings of Forbes (1943) that the non-pregnant cow from about 8 weeks after parturition is able to withstand a period of semi-starvation without developing any marked ketonaemia, as is also true of the dry cow when non-pregnant or in the early stages of pregnancy. A few days of complete starvation also seem to have little effect on such animals. Presumably the glycogen reserves are sufficient to maintain normal metabolism without resorting to excessive breakdown of fat. At the peak of lactation, however, this is not so and on starvation the cow is forced to metabolize considerable quantities of her own fat. Since acetoacetate is formed during the breakdown of the fat molecule (Weinhouse, Medes \& Floyd, I944, I945), it is not surprising to find in cows at the peak of lactation that this is one of the first ketone bodies to appear in quantity, more rapidly in the blood than in the rumen and milk, so that presumably it reaches these latter by diffusion from the blood stream. The same is apparently true of the dry cow in late pregnancy, though in the one animal examined the rise in $\beta$-hydroxybutyric acid and acetone was more marked than that of acetoacetic acid, and the amounts of $\beta$-hydroxybutyric acid were somewhat higher than those encountered during the starvation of a cow at peak lactation.

It has been stated by many workers that acetoacetate is toxic, and certainly the concentration in the blood was small compared to that of free acetone. Shaw, Powell $\&$ White (1942) explained the predominance of acetoacetate in the urine in ketosis by a change in the renal threshold for this substance. As this predominance also occurs on starvation and as acetoacetate is not normally found in the blood stream or urine, it would seem that excess excretion may be due not to a change in renal threshold, but merely to the natural reaction of the kidneys to the presence of a substance with a low renal threshold.

The changes that occur in the rumen and milk of cows starved at peak lactation can be assessed from the relative proportions of the ketone bodies in the blood. The linear regression of concentration of total ketone bodies on days of starvation for the blood, milk and rumen contents (Fig. Io) shows that the three lines are somewhat similar, though the levels vary, being lower in the milk and rumen contents than in the blood. The relative proportions of acetone and isopropanol in the blood and milk are similar, though slightly higher in the latter (Table 4). The mammary gland appears 
to act as an excretory organ ridding the body of some of the excess ketone bodies. There is very little change in either blood or milk in the proportions of acetoacetate over the starvation period, and the proportion of $\beta$-hydroxybutyric acid falls by much the same amount in both fluids. The evidence suggests a direct diffusion from

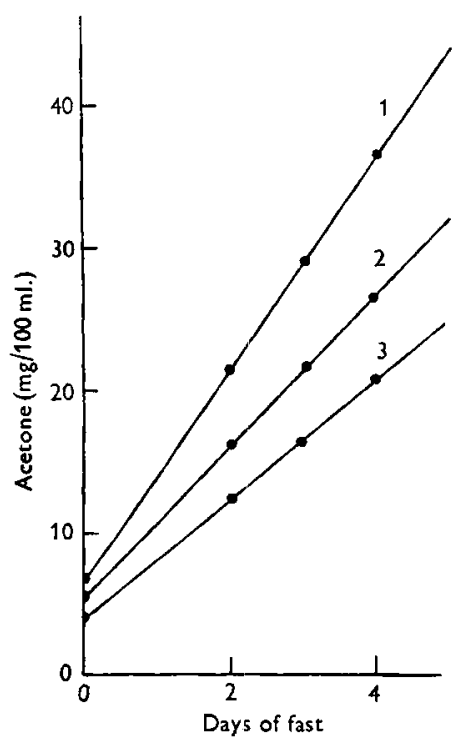

Fig. I0. Regression of concentration of total ketone bodies, expressed as acetone, on days of fast for $I$, blood; 2 , milk; 3 , rumen contents. the blood into the milk with very little, if any, utilization of ketone bodies by the mammary gland, unless perhaps with acetoacetate and $\beta$-hydroxybutyric acid towards the end of the starvation period. According to Shaw (1942) the mammary gland does not utilize acetoacetate but can use $\beta$-hydroxybutyric acid for energy purposes.

The rise in total ketone bodies in the rumen is very much slower than in the blood, but the relative proportions of acetone are very similar, as both show an increase on fasting to about $50 \%$ of the total. In both there is very little change in the proportions of acetoacetate over the starvation period. The rise in the proportion of isopropanol, however, is very much more marked in the rumen than in the blood, as is the fall in $\beta$-hydroxybutyrate.

The acetone bodies probably reach the rumen by way of the saliva and possibly also by direct diffusion. In no case does isopropanol appear in the blood stream before it appears in the rumen contents. This suggests that the site of formation is the rumen, where there is the greatest increase in concentration. The fact that the $\beta$-hydroxybutyric fraction decreases in proportion to the total ketone bodies does not necessarily mean that it is directly or indirectly the precursor of the isopropanol, for as it comprises the bulk of the ketone bodies present in the pre-starvation period a rise in the concentration of any of the others is bound to cause a fall in the relative proportion of this fraction. It should be noted, too, that in the rumen contents the average values for isopropanol remain about half those of free acetone, taken at the same time, over the period covered. This suggests a close relationship between acetone and isopropanol in the rumen, which is in keeping with their chemical composition and acetone may well be a precursor of isopropanol in the rumen. It is, of course, possible that the precursor is some other substance not estimated in these experiments.

Forbes (I943) found that after feeding goats in late pregnancy and cows at the peak of lactation on half rations for ro days, the blood sugar fell steadily from about 50 to $30 \mathrm{mg} / \mathrm{ro0} \mathrm{ml}$. only rising again when full rations were given. Hodgson, Riddell \& Hughes (1932) found that the blood sugar in dairy cattle starved for 9 days fell gradually during that period, and on the 7 th day of starvation started to rise again, only reaching normal a few days after refeeding. In these experiments, it was found that though the blood sugar fell at the beginning of starvation the drop was not significant and that after 2 or 3 days it rose again to the normal level, little change 
being observed on refeeding. The explanation of this discrepancy may lie in the milk production. On starvation, the milk yields of all the cows used in our experiments fell rapidly by amounts ranging from 20 to $60 \mathrm{lb}$. daily, the greatest fall being observed in the highest-yielding cow. Forbes does not mention the milk yields of the cows to which he fed half rations, and it may be that he noted no sudden change, or that he was not interested in the yield. Shaw (1946) recorded a sudden drop in milk yield on starving milking cows but carried out no sugar estimations at that time. Hodgsonet al. (1932) used heifers $1 \frac{1}{2}-2$ years old, so milk production did not enter into their experiments.

A rapid drop in milk yield in a high-yielding cow would presumably conserve body resources, which should help in the maintenance of normal blood levels. In the preceding experiments the starvation was sudden, but even so there was only a temporary fall in blood sugar. It would appear that the blood sugar of an adult milking cow can, as in other species such as man and the dog, find its own level again on starvation, there being at the beginning a temporary upset which the body mechanisms can soon correct.

The results of starving a cow showing signs of subclinical ketosis were in the main very similar to those obtained on starving a normal cow at peak lactation. All the ketone bodies, except isopropanol in the rumen, rose in much the same way over the starvation period. The relative proportions of isopropanol in the rumen fell, though the concentration remained much the same. It will be noted that the concentration of isopropanol in the rumen of the cows with subclinical ketosis was very much the same as that found in a normal lactating cow after 5 days without food; it would appear that either the maximum amount of isopropanol was being produced under these circumstances or the rate of production was being balanced by the rate of metabolism of the component. The blood sugar in these animals did not return to the normal value after the initial drop for some time after refeeding. About a week after refeeding both cows previously suffering from subclinical ketosis were entirely normal.

The ketonaemia produced in ewes in late pregnancy was similar to that found in lactating and pregnant cattle. The lower percentages of both acetone and isopropanol in the ewe and cow in late pregnancy support the association between these two components previously mentioned and indicate that in late pregnancy neither the cow nor the sheep produce acetone in the same quantities as the cow at peak lactation.

If the ketosis observed on starvation was due primarily to excessive katabolism of body fat, with the production of abnormal quantities of acetoacetic acid, then it would appear that both the cow and the sheep in late pregnancy converted the bulk of this fraction into $\beta$-hydroxybutyric acid by reduction, the remainder being decarboxylated to acetone. The cow at peak lactation, on the other hand, appeared to produce acetone and $\beta$-hydroxybutyric acid in about equal proportions from acetoacetic acid, and so was able to form a higher percentage of isopropanol.

It would appear that the dry non-pregnant cow, or one producing little milk, gives much the same response to starvation as the steer, in that no appreciable rise in blood and urinary ketone bodies occurs. The cow at the peak of lactation or the cow or 
sheep in late pregnancy, however, responds to starvation in a manner entirely different from that found in the dry non-pregnant cow, steer (Carpenter, 1927), man (Wick, Sherrill \& MacKay, r940; Crandall, I941 and Crandall, Ivy \& Ehni, 1940-r), dog (Crandall, I94I and Crandall, Ivy \& Ehni, I940-1), or rat (Wick et al. 1940), in that the level of total ketone bodies found in the blood is still rising after 5 days of starvation. If the suggestion of Wick et al. (1940) is true that the stabilization in the blood of the total ketone-body level attained after a few days in man and rat is due to the production of carbohydrate from tissue protein and fat, then it would appear that the cow at peak lactation or cow or sheep in late pregnancy is unable to produce, when starved, sufficient carbohydrate from these sources to maintain the blood sugar and keep down the ketone-body levels, even with a drop in milk yield in the lactating animal. This may be associated entirely with greater demands for carbohydrate in late pregnancy or in lactation even at a reduced level. Alternatively the mechanisms for bringing such compensatory changes into play may be less effective in the ruminant, or the demands of the foetus or of a high milk yield may have depleted the available reserves to such an extent as to hinder the attainment of equilibrium.

The chain of events suggested by the above observations is primarily the formation of acetoacetate from the katabolism of fat and its rapid excretion or conversion into acetone and $\beta$-hydroxybutyric acid. These various fractions reach the blood stream whence they pass into the milk and urine and also the rumen. In this organ there occurs the formation of $i$ sopropanol, probably from acetone, which then passes back into the blood stream and eventually reaches the milk and urine, though at very low levels.

\section{SUMMARY}

I. The effect of starvation on the rumen contents of five cows at peak lactation was to produce a sharp fall in the total volatile fatty-acids, accompanied by a rise in $\mathrm{pH}$, which was presumably associated with decreased bacterial activity.

2. Five lactating animals showed a rapid and significant fall in milk yield on starvation.

3. Five lactating cows and two cows in the last month of pregnancy showed a progressive and highly significant degree of ketonaemia on starvation. Two non-lactating and non-pregnant cows starved completely and one lactating cow fed on a maintenance diet only showed less change in blood ketones. Two cows with subclinical ketosis and two pregnant ewes gave results similar to those in the normal lactating bovine.

4. The site of origin of the isopropanol unlike that of acetone, acetoacetic acid and $\beta$-hydroxybutyric acid was most probably the rumen, and its likely precursor acetone.

5. The ketonaemia produced in starving ruminants appeared to be more marked than that recorded in other species, but the response of the blood sugar to starvation was found to be much the same as that in other animals.

6. The significance of these findings is discussed.

We are indebted to the Agricultural Research Council for a grant which defrayed the costs of this investigation. 


\section{REFERENCES}

Carlström, B. (1950). Vet. Rec. 62, 717.

Carpenter, T. M. (1927). Amer. F. Physiol. 31, 5 I9.

Clark, R., Groenewald, J. W. \& Malan, J. R. (1943). Onderstepoort J. vet. Sci. 18, 263.

Crandall, L. A. Jr. (1941). F. biol. Chem. 138, 123.

Crandall, L. A. Jr., Ivy, H. B. \& Ehni, G. J. (r940-I). Amer. F. Physiol. r3r, ro

Elsden, S. R. (1946). Biochem. F. 40, 252.

Forbes, R. M. (1943). Cornell Vet. 33, 27.

Friedemann, T. E. (1938). F. biol. Chem. 123, I61.

Hagedorn, H. C. \& Jensen, B. N. (1923). Biochem. Z. 137, 92.

Hodgson, R. E., Riddell, W. H. \& Hughes, J. S. (1932). F. agric. Res. 44, 357.

Holmes, J. R. (1950). Vet. Rec. 62, 724.

McAnally, R. (1941). F. exp. Biol. 20, 130.

Robertson, A., Thin, C. \& Stirling, A. (1950). Nature, Lond., 166, 954.

Sampson, J. \& Boley, L. E. (1940). Cornell Vet. 30, 392.

Shaw, J. C. (1942). F. biol. Chem. 142, 53.

Shaw, J. C. (1946). F. Dairy Sci. 29, 183.

Shaw, J. C., Powell, R. C. Jr. \& White, G. C. (1942). F. Amer. vet. med. Ass. roo, 473.

Sjollema, B. \& Van der Zande, J. E. (r923). F. metab. Res. 4, 525.

Somogyi, M. (1930). F. biol. Chem. 86, 655.

Thin, C. \& Robertson, A. (1952). Biochem. F. 51, 2 I 8.

Weinhouse, S., Medes, G. \& Floyd, N. F. (1944). F. biol. Chem. 155, 143.

Weinhouse, S., Medes, G. \& Floyd, N. F. (1945). F. biol. Chem. 158, 4I I.

Wick, A. N., Sherrill, J. W. \& MacKay, E. M. (1940). Proc. Soc. exp. Biol., N. Y., 45, 437. 